\title{
Pathogenic mutations in neurofibromin identifies a leucine-rich domain regulating glioma cell invasiveness
}

\author{
Siti Farah Bte Fadhlullah ${ }^{1,11}$ - Nurashikin Bte Abdul Halim ${ }^{1} \cdot$ Jacqueline Y. T. Yeo ${ }^{1} \cdot$ Rachel L. Y. Ho $^{1} \cdot$ Phoebe Um $^{1,2}$. \\ Beng Ti Ang ${ }^{3,4,5,6} \cdot$ Carol Tang ${ }^{7,8,9} \cdot$ Wai H. Ng$^{3} \cdot$ David M. Virshup $\mathbb{1}^{8,10} \cdot$ Ivy A. W. Ho $\mathbb{1}^{1,4,6}$
}

Received: 24 July 2018 / Revised: 14 March 2019 / Accepted: 23 March 2019 / Published online: 9 April 2019

(c) The Author(s) 2019. This article is published with open access

\begin{abstract}
Glioblastoma (GBM) is the most aggressive tumor of the brain. NF1, a tumor suppressor gene and RAS-GTPase, is one of the highly mutated genes in GBM. Dysregulated NF1 expression promotes cell invasion, proliferation, and tumorigenesis. Loss of $\mathrm{NFI}$ expression in glioblastoma is associated with increased aggressiveness of the tumor. Here, we show that NF1loss in patient-derived glioma cells using shRNA increases self-renewal, heightens cell invasion, and promotes mesenchymal subtype and epithelial mesenchymal transition-specific gene expression that enhances tumorigenesis. The neurofibromin protein contains at least four major domains, with the GAP-related domain being the most well-studied. In this study, we report that the leucine-rich domain (LRD) of neurofibromin inhibits invasion of human glioblastoma cells without affecting their proliferation. Moreover, under conditions tested, the NF1-LRD fails to hydrolyze Ras-GTP to Ras-GDP, suggesting that its suppressive function is independent of Ras signaling. We further demonstrate that rare variants within the NF1-LRD domain found in a subset of the patients are pathogenic and reduce NF1-LRD's invasion suppressive function. Taken together, our results show, for the first time, that NF1-LRD inhibits glioma invasion, and provides evidence of a previously unrecognized function of NF1-LRD in glioma biology.
\end{abstract}

\section{Introduction}

Glioblastoma (GBM) is the most malignant tumor of the brain with patients having a median survival of less than 15 months [1, 2]. Current standard therapy after initial diagnosis, includes maximal surgical debulking followed by

Supplementary information The online version of this article (https:// doi.org/10.1038/s41388-019-0809-3) contains supplementary material, which is available to authorized users.

Ivy A. W. Ho

ivy_aw_ho@nni.com.sg

1 Molecular Neurotherapeutics Laboratory, National Neuroscience Institute, Singapore 308433, Singapore

2 University of Pennsylvania, Philadelphia, PA 19104, USA

3 Department of Neurosurgery, National Neuroscience Institute, Singapore 308433, Singapore

4 Department of Physiology, Yong Loo Lin School of Medicine, National University of Singapore, Singapore 119228, Singapore

5 Singapore Institute for Clinical Sciences, A*STAR, Singapore 117609, Singapore adjuvant temozolomide administration and radiation therapy. However, due to the highly infiltrative and heterogeneous nature of the tumor cells, invading cells render complete surgical resection impossible, making recurrence of tumor growth an intractable clinical issue [3, 4].

The tumor suppressor gene $N F 1$ is mutated or suppressed in a variety of sporadic cancers such as neuroblastoma, melanoma, and nonsmall-cell lung cancer [5-9]. Notably, $N F 1$ is mutated or deregulated in approximately 13\% of GBM, ranking it the third most frequently somatically mutated gene

6 Duke-NUS Medical School, Singapore 169857, Singapore

7 Department of Research, National Neuroscience Institute, Singapore 308433, Singapore

8 Program in Cancer and Stem Cell Biology, Duke-NUS Medical School, Singapore 169857, Singapore

9 Division of Cellular and Molecular Research, National Cancer Centre, Singapore 169610, Singapore

10 Department of Pediatrics, Duke University School of Medicine, Durham, NC 27703, USA

11 Present address: Lucence Diagnostics Pte Ltd., Singapore, Singapore 
sequence in GBM [10-12]. These mutations, include nonsense mutations, splice site mutations, frameshift indels, and missense mutations. In GBM, NFI loss or mutation is observed primarily in the more aggressive mesenchymal subtype, suggesting its role as a driver of mesenchymal transition [13-17].

Neurofibromin, the protein product of the $N F 1$ gene, is a RAS GTPase-activating protein (RAS-GAP) that negatively regulates Ras activity by catalyzing the hydrolysis of RASGTP $[18,19]$. Deregulated Ras expression thus results in activation of downstream proteins and transcription factors, some of which are associated with the epithelialmesenchymal transition (EMT). EMT-associated transcription factors such as SNAIL (SNAI1), SLUG (SNAI2), Twist Family BHLH Transcription Factor (TWIST)-1, Zinc Finger E-Box Binding Homeobox (ZEB) have been shown to be upregulated in malignant peripheral nerve sheath tumor (MPNST) deficient for neurofibromin [20, 21]. Loss of $N F 1$ also triggers the activation of multiple signaling pathways, including Rho/Rho associated coiled-coil containing protein Kinase (ROCK)/LIM domain kinase (LIMK) signaling that promotes changes in actin cytoskeleton, thereby regulating cellular motility [22]. LIMK2 is a microtubule-associated protein that enhances microtubule stability when it is unphosphorylated. It has been suggested that the binding of SEC14-Plekstrin Homology (PH) domain of neurofibromin to LIMK2 prevents activation of LIMK2 by ROCK, thereby resulting in reduced actin polymerization and inhibition of cell invasion. On the other hand, in NF1-null cells, LIMK2 is hyperphosphorylated by ROCK, leading to enhanced cell migration and invasion [22]. Downregulation of neurofibromin not only encourages EMT transition, it also promotes intrinsic resistance to inhibitors along the Ras-RAF-MEK-ERK pathway by RAS activation $[8,23,24]$. Mutation in the $B R A F$ variant V600E, upregulation of receptor tyrosine kinases (RTK) such as epidermal growth factor receptor or activation of mitogen activated protein kinase (MEK) are some of the mechanisms of resistance in NF1 mutant or deficient tumors [8, 10, 25-27]. Recent studies found that MEK inhibitor (MEKi), such as Sorafenib, are effective in NFl-associated MPNST [28]. However, despite its antitumor efficacy in MPNST in vitro [28-30], it fails to deliver therapeutic benefit in the clinics [31]. On the other hand, the MEKi Selumetinib, appears to be beneficial for children with neurofibromatosis 1 (NF1) [32]. The limited efficacy of MEKi suggested that single agent MEKi is insufficient to combat cancer growth, and MEKi may require other combinations such as mTORC1/2 inhibitors to be effective [33].

Neurofibromin has multiple domains, with the GAPrelated domain (GRD) being the most well-studied. Other key functional domains involved in neurofibromin function, include the leucine-rich domain (LRD), the cysteine-serine rich domain (CSRD), and the C-terminal domain (CTD) $[34,35]$. Each domain interacts with various effectors to modulate cellular functions. For example, binding of GRD to sprouty-related EVH1 domain-containing protein 1 (Spred1) inhibits Spred1 function and localizes GRD to the membrane to inactivate membrane-anchored Ras [36]. The CTD domain, on the other hand, regulates neurite outgrowth and dendritic filopodia formation through its interaction with collapsin response mediator proteins (CRMP)-2 and $-4[37,38]$ and syndecan-2, respectively [39]. CTD also mediates cell adhesion through its binding with focal adhesion kinase [40]. Both CTD and CSRD interact with dimethylarginine dimethylaminohydrolase 1 (DDAH1), which degrades the endogenous nitric oxide inhibitor asymmetric dimethylarginine (ADMA) responsible for regulating cell proliferation [35]. The LRD domain spans amino acids (aa) 1579-1971 (UniProtKB-P21359; neurofibromin isoform 2) and consists of a known SEC14-PH domain and a portion of the HEAT-like repeats (HLR) or the structurally related Armadillo (ARM) superfamily $[35,41]$. Based on structural and biochemical analysis, the bipartite SEC14-PH domain was shown to bind to phospholipids [42, 43]. The NF1-LRD domain was first shown by Wang et al. to regulate dendritic spine formation through its interaction with valosin-containing protein [41]. They further demonstrated that c.4759_4761delTAT; Y1587 (delta) mutation observed in the NF1-LRD domain almost completely abolished this interaction.

In the current study, we show that the NF1-LRD plays a critical role in suppressing glioma cell invasion both in vitro and in an orthotopic glioma mouse model. We further demonstrate that pathogenic mutations within this domain abolish its invasion suppression function, suggesting a role for the NF1-LRD against tumor metastasis and invasion.

\section{Results}

\section{Inverse relationship between NF1-expression levels and invasive aggressiveness}

To assess the expression of NF1 in GBM subtypes, we analyzed The Cancer Genome Atlas (TCGA) database. NFI expression was significantly lower in the more aggressive mesenchymal GBM in comparison to other subtypes as shown in TCGA GBM database analysis $(n=203)$ (Fig. 1a). This finding confirms previous reports that showed NF1 correlation with mesenchymal GBM [3, 44]. We further supported this finding at the protein level by immunostaining performed using patient-derived GBM tumor sections for neurofibromin expression. Clear nucleus and cytoplasmic staining were observed in the proneural 
A

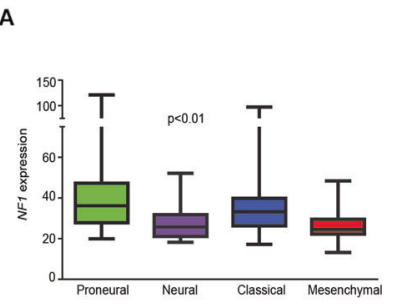

B

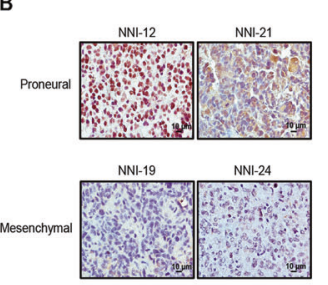

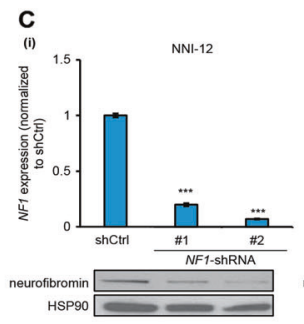

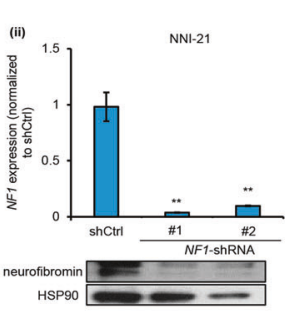

D

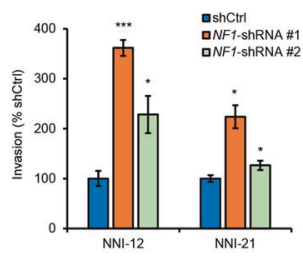

E (i)
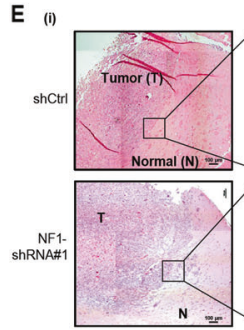

(ii)

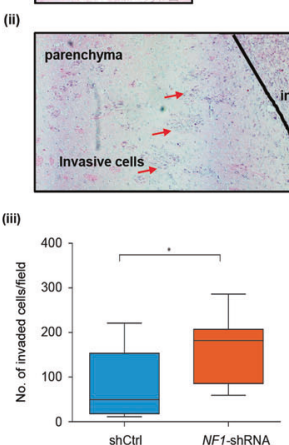

$\mathbf{F}$

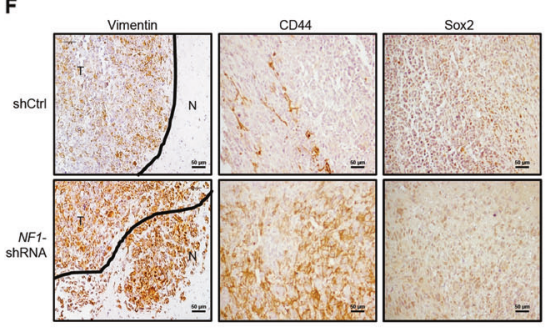

G

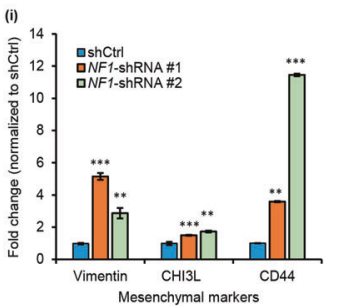

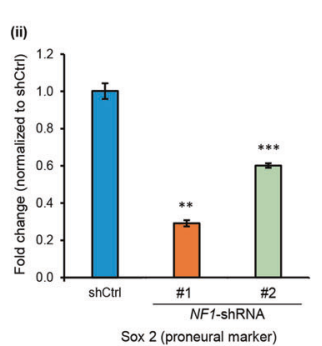

H

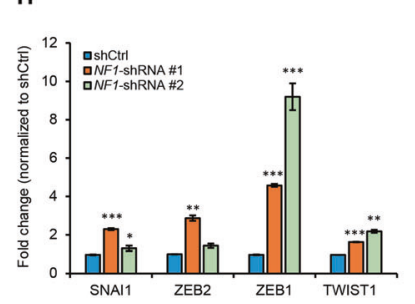

$\mathbf{I}$

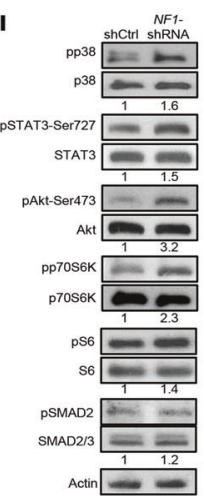

Fig. 1 NF1 loss promotes GPCs invasion in vitro and in vivo. a NF1 mRNA expression in GBM subtypes. One-way ANOVA with Tukey's test was used to analyze statistical significance, $* p<0.01$. Data are represented as mean $\pm \mathrm{SD}$. b Neurofibromin expression in patientsderived tumor xenograft. Scale bar $=50 \mu \mathrm{m}$. $\mathbf{c} N F 1 \mathrm{mRNA}$ and protein expression in NF1-shRNA\#1 and \#2-transduced (i) NNI-12 and (ii) NNI-21. HSP90 serves as the loading control. d Percentage of invasion in NF1-shRNA \#1 and \#2-transduced NNI-12 and NNI-21. e (i) Photomicrographs show H\&E staining and neurofibromin expression in shCtrl (top) and NF1-shRNA\#1(bottom)-transduced tumor. Black line, invasion zone between tumor and normal; red arrows, pocket of invasive cells; $\mathrm{T}$ tumor, $\mathrm{N}$ normal. Scale bar $=25 \mu \mathrm{m}$. (ii) Photomicrographs show composite of seven images demonstrating the extent of invasion in NF1-shRNA-transduced tumor. Red arrow, pocket of invasive cells; black line, invasion zone betwen normal and tumor region. Scale bar $=50 \mu \mathrm{m}$. (iii) Quantification of the number of invaded cells in shCtrl and NF1-shRNA-transduced tumor. Data shown are absolute value per field (200× original magnification).

GBM NNI-12 and NNI-21, but were largely absent in the mesenchymal GBM NNI-19 and NNI-24 (Fig. 1b).

Genetic modeling of mesenchymal GBM in mice has been achieved by concurrent deletion or mutation of $N F 1$, p53, and/or PTEN [14, 45, 46]. As such, to investigate the role of NF1 in glioma invasion in this study, both $p 53$ and NF1 transcripts were depleted using shRNAs (Supplemental Fig. 1 and Fig. 1c). NF1 expression was knocked down
Student's $t$ test was used to analyze statistical significance between $N F 1$-shRNA and shCtrl-transduced tumor, $* * p<0.001$. f Immunohistochemistry staining shows Vimentin, CD44 and Sox 2 expression in shCtrl (top) and NF1-shRNA (bottom) transduced tumor. Scale bar $=50 \mu \mathrm{m}$. $\mathrm{g}$ mRNA expression of (i) Vimentin, CHI3L and CD44, and (ii) Sox 2 in shCtrl and NF1-shRNAs-transduced cells as determined by qPCR. $\mathbf{h}$ qPCR analysis of EMT markers SNAI1, ZEB2, ZEB1, and TWIST1 in shCtrl and NF1-shRNA-transduced cells. i Western blot analysis demonstrating expression of p38, STAT3, AKT, p70S6K, S6, SMAD2 in NNI-21 cells transduced with shCtrl and NF1-shRNA $72 \mathrm{~h}$ post-infection. Actin serves as the loading control. Densitometry quantification was done for the indicated proteins by normalizing to actin. Ratios were indicated below each blot. For (c), (d), (g), and (h), data presented are representative from three independent experiments \pm SEM. Student's unpaired $t$ test was used to analyze statistical significance between $N F 1$-shRNA and shCtrltransduced cells, $* p<0.01, * * p<0.001, * * * p<0.0001$

using two independent lentiviral shRNAs in two NF1expressing patient-derived glioma propagating cells (GPCs). These GPCs were derived from patient-glioma and characterized as previously described [47-50]. Lentiviral transduction of NF1-shRNA-\#1 and NF1-shRNA-\#2 resulted in more than $90 \%$ depletion of $N F 1$ mRNA and protein as confirmed with quantitative polymerase chain reaction (qPCR) and western blot (Fig. 1c). Morphological 
changes in self-renewal and proliferation after transduction were analyzed by colony forming assay. Depletion of $N F 1$ resulted in higher self-renewal capability as shown by an increase in the percentage of neurospheres formed in comparison with those of shControl (shCtrl)-transduced cells (Supplemental Fig. 2A). Morphological changes were further evidenced in the higher number of GFP-expressing GPCs (Supplemental Fig. 2B). In addition, these spheres were also larger in size than those of the shCtrl-transduced cells. We further demonstrated that NF1-knockdown GPCs proliferate faster than the shCtrl-transduced cells (Supplemental Fig. 2C and D), indicating that NF1-loss promotes GPCs self-renewal and proliferation. Of note, the extent of neurosphere formation and clonogenicity was more prominent in NF1-shRNA\#1.

\section{NF1 loss promotes GPCs infiltration and exacerbates their ability to invade in vitro and in vivo}

We investigated the effect of NF1 downregulation on invasiveness in NF1-positive NNI-12 and NNI-21 GPCs. Increased invasion was observed in both GPCs transduced with the two NF1-shRNAs but not with shCtrl lentivirus, indicating that loss of $N F 1$ promotes cell invasion (Fig. 1d). To evaluate whether NFI knockdown induces invasion in vivo, we implanted $N F 1$-knockdown NNI-21 GPCs into immunodeficient NOD.SCID Il2 $\mathrm{r}^{-1-}$ (NSG) mice. In agreement with our in vitro findings, $N F 1$ silencing markedly increased the number of invasive tumor clusters (red arrows) in comparison to the shCtrl-implanted mice (Fig. 1e (i) and (iii), Supplemental Fig. 3). NFI-silenced GPCs colonized the proximal brain hemisphere 9 weeks postimplantation, with invasive cells observed at the parenchyma and invasion zone (Fig. 1e(ii), red arrows). We also tested a panel of three IHC markers which showed differential expression patterns in human proneural vs. mesenchymal glioma (Fig. 1f). These markers, include proneural marker SOX2 [51], and mesenchymal markers vimentin [52], CD44 [53], and chitinase-3-like protein (CHI3L)/YKL40 [44]. Our results showed that NF1knockdown tumor had higher percentage of vimentin and CD44-positive cells (Fig. 1f). Conversely, a lower percentage of SOX2-positive cells was observed in the NF1knockdown tumor (Fig. 1f). Quantification of mesenchymal and proneural markers was performed using qPCR. As expected, higher levels of vimentin, $C H I 3 L$ and $C D 44$ were observed in NF1-shRNAs-transduced cells (Fig. 1g(i)), while SOX2 mRNA was higher in shCtrl-transduced cells (Fig. 1g(ii)). We additionally investigated whether NFIknockdown promotes EMT by examining changes in EMT markers expression. NFl knockdown significantly increased the expression of EMT markers (SNA1, ZEB2, ZEB1, and TWIST1) (Fig. 1h), suggesting the activation of
EMT-associated signaling pathway. Of the known effectors of NF1-loss associated signaling, p38, STAT3, AKT, mTOR, and TGF- $\beta$ have been previously linked to heightened tumor aggressiveness. We therefore assessed STAT3, AKT, p70S6Kinase, and TGF- $\beta$ in NF1-knockdown cells by measuring their activated forms by western blot (phosphorylated(p)—p38, p-STAT3, p-AKT, p-p70S6Kinase, p-S6, p-SMAD2). p-p38, p-STAT3, p-S6, and p-SMAD2 were marginally increased in $N F 1$-knockdown cells, suggesting that these pathways do not play a major role in our system. In stark contrast, levels of p-AKT were low in shCtrl cells, but greatly increased in cells that were transduced with $N F 1$-shRNA, suggesting the possible involvement of the AKT signaling pathway (Fig. 1i), supporting our results that NFI loss promotes cell proliferation. Collectively, these results demonstrated that $N F 1$-loss promotes GBM infiltration and exacerbates their invasive ability.

\section{NF1-LRD expression reverts cell invasion}

Neurofibromin contains four major domains, namely CSRD, GRD, LRD, and CTD (Fig. 2a(i)) [54]. To determine whether NF1-loss mediated invasion is reversible, we overexpressed these domains of neurofibromin in neurofibromin-deficient LN229 human glioma cells [6]. Because domain-specific antibodies are not available, each domain was tagged with hemagglutinin (HA) for western blot detection (Fig. 2a(ii)). To test the effects of these domains on glioma cell invasion, we transfected the expression plasmids into LN229 cells and assessed the invasion capability. In comparison to the vector control, overexpression of NF1-LRD in LN229 human glioma cells reduced invasion by approximately $80 \%$ (Fig. 2b). By contrast, NF1-GRD overexpression reduced invasion by $30 \%$, possibly due to its effect on cell proliferation, while expression of the NF1-CTD and NF1-CSRD domains had no specific effect on cell invasion, suggesting that the cell invasion may be Ras-independent. To further test this, we overexpressed NF1-GRD and NF1-LRD domain in LN229 cells followed by stimulation with recombinant epidermal growth factor (EGF) to assess the Ras-GTPase activity. Remarkably, higher levels of Ras-GTP were observed in NF1-LRD-transfected cells treated with EGF, demonstrating that the NF1-LRD likely played no role in Ras-GAP activity of neurofibromin (Supplemental Fig. 4). We further investigated whether the NF1-LRD played a role in cell proliferation. In comparison to the NF1-GRD where the percentage of proliferation decreased from 24 to $72 \mathrm{~h}$, expression of the NF1-LRD did not inhibit cell proliferation, demonstrating that proliferation activity and invasion capacity were uncoupled (Fig. 2c).

Given that NF1-LRD suppresses cell invasion in neurofibromin-deficient LN229, we were interested in 


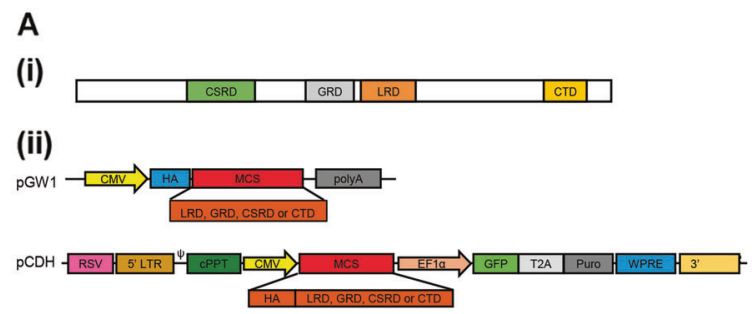

B

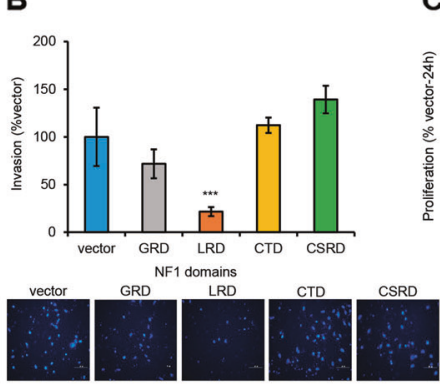

C

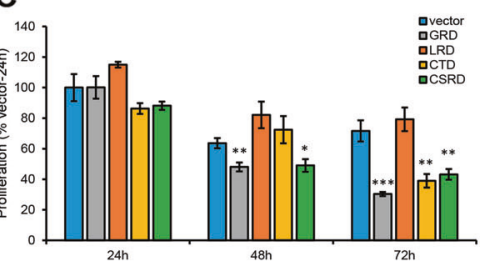

(iii)

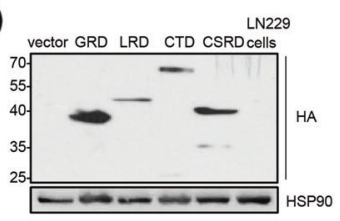

D

(i)

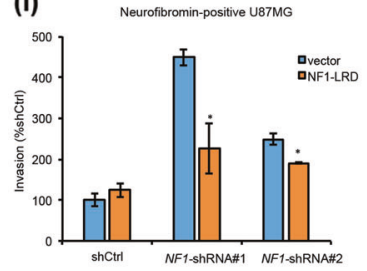

(iii)

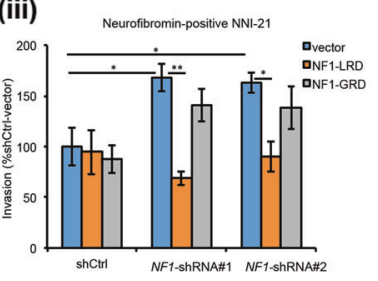

(ii)
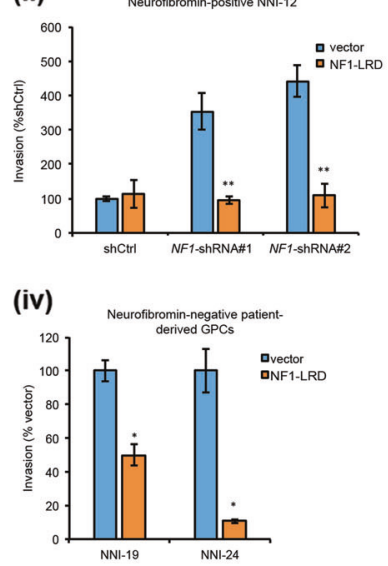

E

(i)

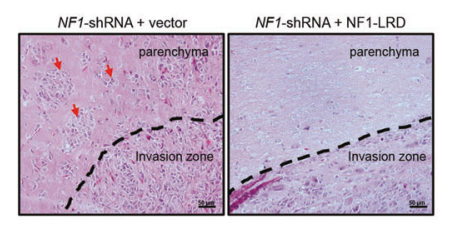

(ii)

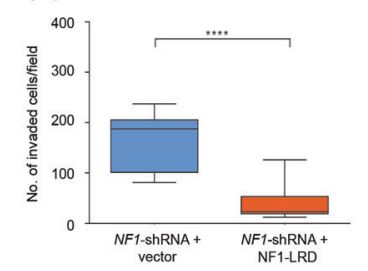

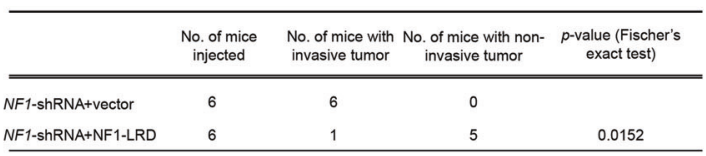

Percentage of cell proliferation was normalized to that of vectortransfected cells at $24 \mathrm{~h}$. d Invasion assay was performed on (i) U87MG, (ii) NNI-12, (iii) NNI-21 and (iv) neurofibromin-negative patient-derived GPCs. e (i) Photomicrographs show H\&E staining of NF1-shRNA vector or NF1-LRD-transduced tumor. Red arrows, pocket of invasive cells; black line, invasion zone between tumor and normal region of the brain. Scale bar $=50 \mu \mathrm{m}$. (ii) Quantification of the number of invaded cells in NF1-shRNA vector or NF1-LRDtransduced tumor per field (200x original magnification). The number of mice with non-invasive tumor in NF1-shRNA- NF1-LRDtransduced tumor was summarized in the table. Statistical significance was analyed using Fischer's exact test. All data are represented as mean \pm SEM. Student's unpaired $t$ test was used to analyze statistical significance between NF1-LRD and vector, ${ }^{*} p<0.01$, $* * p<0.001, * * * p<0.0001, * * * * p<0.00001$

NNI-12, whereby re-expression of NF1-LRD suppressed invasion by $\sim 70 \%$ (Fig. $2 \mathrm{~d}(\mathrm{ii})$ ). To evaluate whether the effect observed was specific to the NF1-LRD, we transduced NF1-knockdown NNI-21 GPCs with NF1-GRD, NF1-LRD, and $\mathrm{pCDH}$ vector and compared their invasive capacities. In contrast to NF1-LRD-re-expressing cells, NF1-GRD failed to inhibit NF1-loss-induced cell invasion (Fig. 2d(iii)). The percentage of invasion in NF1-GRDtransduced cells was similar to that of the vector control, indicating that the ability to suppress cell invasion was 
NF1-LRD-specific. We further assessed the effect of reexpressing NF1-LRD in GPCs that did not express neurofibromin (i.e., NNI-19 and NNI-24). As shown in Fig. 2d (iv), NF1-LRD inhibited invasion of NNI-19 and NNI-24 by $50 \%$ and $90 \%$, respectively.

To test whether re-expression of NF1-LRD suppresses invasion in vivo, we transduced NF1-LRD into NF1knockdown NNI-21 GPCs and assessed the extent of tumor invasion. As shown in Fig. 2e, NF1-LRD significantly inhibited invasion in vivo. In comparison to NFl-shRNA vector-transduced cells, clear demarcation between tumor and normal region was observed in NF1-LRD-expressing tumor (Fig. 2e), whereas invasive cells were notably visible in NF1-shRNA vector-transduced tumors (red arrows). Quantification carried out to determine the extent of cell invasion showed significantly higher number of invaded cells in vector-transduced NF1-knockdown tumor in comparison to those re-expressing NF1-LRD (Fig. 2e(ii)). In fact, five out of six mice implanted with NF1-LRD-transduced cells were presented with non-invasive, highly circumscribed tumors when compared with mice implanted with the vector. Taken together, these results demonstrated that NF1-LRD reverts cell invasion.

\section{NF1-LRD reverses EMT markers expression}

We previously showed that loss of NF1 upregulates expression of EMT markers and mesenchymal markers. To assess whether decreased invasion observed in vitro and in vivo is associated with changes in EMT markers expression, we performed qPCR to assess the transcript levels of EMT markers genes SNAII and ZEB2. Our results showed lower levels of SNAII and ZEB2 in NF1shRNA-knockdown cells expressing NF1-LRD when compared with the vector control (Fig. 3a). Similarly, Vimentin and CD44 expression were also lower in NF1$L R D$-expressing cells, while SOX2 expression was elevated (Fig. 3b). To rule out the effect of cell culture, we additionally assessed the expression of SOX2, Vimentin and CD44 protein in NF1-LRD-expressing tumor. Similar to qPCR results, a higher percentage of SOX2-positive cells was observed in NF1-LRD-expressing tumor (Fig. 3c, d(i)), while that of Vimentin was lower (Fig. 3c, d(ii)), likely indicating a delayed proneural to mesenchymal transition in the NF1-shRNA transduced cells. In contrary to the elevation of CD44 mRNA transcripts observed in vitro, no significant difference in $C D 44$ expression was observed between vector and NF1-LRD-expressing NF1shRNA-transduced tumor (Fig. 3c, d(iii)). Taken together, these results suggested that re-expression of NF1-LRD may revert EMT by downregulating EMT-associated transcription factor activity following NF1 loss.

\section{Pathogenic mutations in the NF1-LRD domain abolish suppression of invasion}

We then sought to investigate whether mutations, specifically nonsense or missense mutations, found within the NF1-LRD domain will affect the invasiveness of glioma cells. By querying cBioportal TCGA GBM database $[11,12]$, we identified two mutations within the NF1-LRD domain that were also found in other cancer types such as cutaneous melanoma, colon carcinoma, and infiltrative breast carcinoma (cBioportal TCGA database, Tumor suppressor gene database, NCBI dbSNP, ClinVar, and Human Proteome Variation Database). Using site-directed mutagenesis, we generated two mutants that carry the D1849N (missense) and W1952* (nonsense) mutations (Fig. 4a). We expressed these mutants or wild-type (wt) NF1-LRD in the neurofibromin-deficient LN229 and U251MG cells [6] and compared their invasiveness. Both W1952* and D1849N restored cell invasion in LN229 and U251MG, though to a different extents (Fig. 4b(i) and (ii)). However, enforced expression of NF1-LRD reduced cell invasion by approximately $70 \%$ (Fig. $4 \mathrm{~b}$ (i) and (ii)) in comparison to the vector control. We further examined the effect of NF1-LRD expression in the neurofibromin-deficient GBM of mesenchymal subtype from NNI-19 and NNI-24 GPCs (Fig. 4c(i) and (ii)). Consistent with LN229 and U251MG, re-expression of W1952* and D1849N failed to suppress cell invasion when compared to GPC re-expressing NF1LRD, thus demonstrating that patient-derived mutations abrogate the biological activity of the NF1-LRD domain.

\section{C-terminal region of NF1-LRD is required for suppressing cell invasion}

We mapped the regions of NF1-LRD that are required for suppressing cell invasion using a series of truncation mutants that span different regions of NF1-LRD (Fig. 5a). These mutants ranged in size from 7 to $33 \mathrm{kDa}$ with similar expression level as shown by HA immunoblotting with the exception of LRD 1839-1881 (7 kDa) (Fig. 5b). We investigated the extent of cell invasion exhibited by these truncation mutants based on the number of HA+ cells vs. HA - cells followed by normalizing to vectortransfected cells. Our results showed that LRD 1579-1738 which contains the SEC14 domain, exhibited comparable level of invasion suppression to wt-LRD. By contrast, the SEC14-PH domain-containing-LRD 1579-1843 and the PH domain-containing-LRD 1739-1843 did not significantly suppress invasion as compared to wt-LRD. Remarkably, LRD 1839-1881 and LRD 1882-1971 displayed the strongest suppression of invasion when compared with the wt-LRD ( $\sim 80$ vs. $\sim 50 \%$; Fig. $5 \mathrm{c}(\mathrm{i})))$. It is 
A

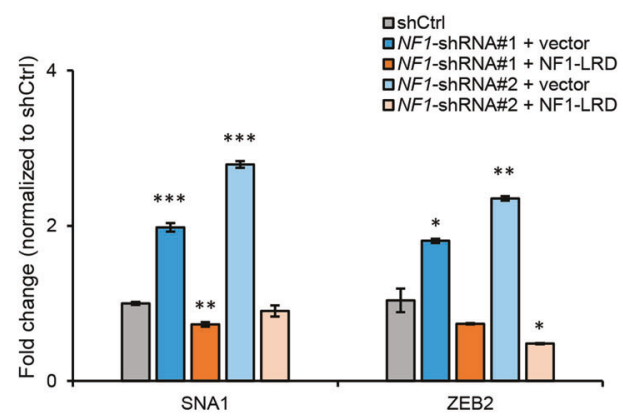

C

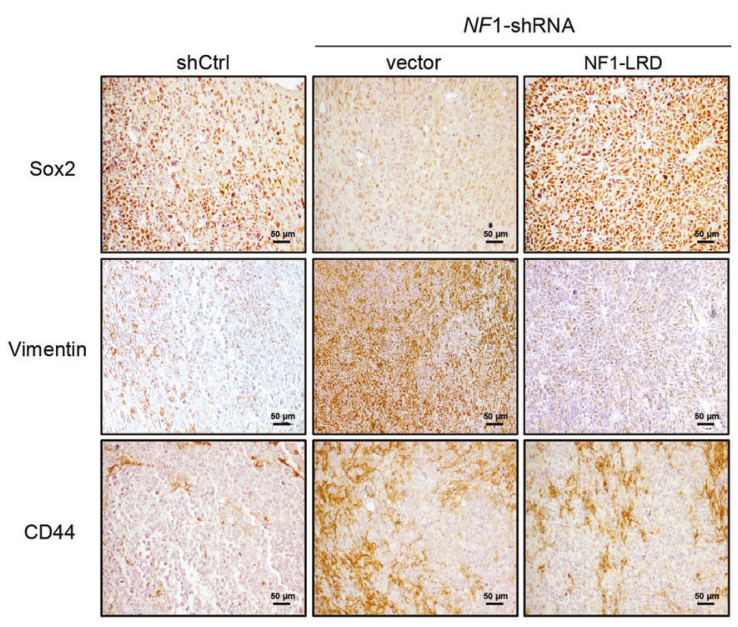

Fig. 3 NF1-LRD reverses EMT markers expression. The expression of a SNAI1 and ZEB2, b Vimentin, CD44, and Sox2 were assessed in NF1-shRNA-vector or NF1-shRNA-NF1-LRD-transduced NNI-21 GPCs. Data shown are fold change of mRNA expression normalized to shCtrl. Data are presented as mean \pm SEM. Student's unpaired $t$ test was used to analyze statistical significance between $N F 1-L R D$ and vector, ${ }^{*} p<0.01, * * p<0.001, * * * p<0.0001$. c Immunohistochemistry

D

(ii)
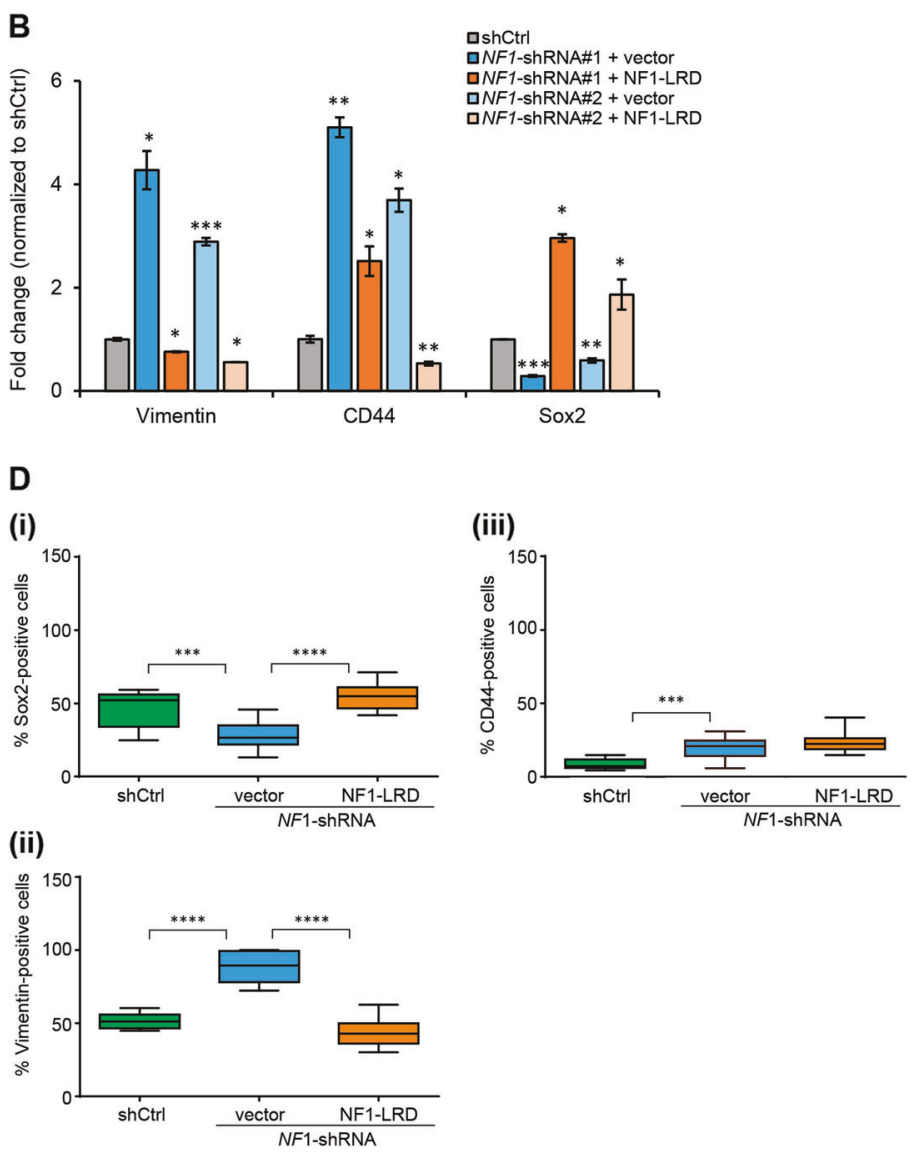

staining of Sox2, Vimentin, and CD44 in NF1-shRNA-vector or NF1shRNA-NF1-LRD-transduced NNI-21 tumor. Scale bar $=50 \mu \mathrm{m}$. d Quantification of (i) Sox2, (ii) Vimentin, and (iii) CD44-positive cells from IHC staining. One-way ANOVA followed by Bonferroni's post hoc test was performed to analyze statistical significance. ${ }^{*} p<0.01$, $* * p<0.001, * * * p<0.0001$ interesting to note that the expression levels of LRD 1839-1881 were the lowest among the truncation mutants (Fig. 5b), suggesting that this region may be critical for NF1-LRD's function.

Because D1849N and W1952* mutations fall within LRD 1839-1881 and LRD 1882-1971 fragments, respectively, we employed site-directed mutagenesis to introduce these mutations into both fragments and compared their role in cell invasion (Fig. 5d(i) and (ii)). Our results demonstrate that LRD 1882-1971-W1952*, with a molecular weight of $10.5 \mathrm{kDa}$ (Fig. 5d(ii)), restored cell invasion in comparison to its wt counterpart (Fig. 5e; $112.2+12.5 \%$ vs. $29.4 \pm$ $6.3 \%$ ). Similarly, the suppressive effect was lost in cells transfected with LRD 1839-1881-D1849N as opposed to its wt counterpart ( $\%$ invasion are $75.5 \pm 2.12 \%$ vs. $26.6 \pm$ $5.7 \%$, respectively, $p=0.027$; Fig. 5e). Taken together, these results indicated that the LRD region from 1839-1971 is critical for suppressing glioma cell invasion.

\section{Discussion}

Cellular invasion is the key hallmark of GBM that is highly associated with tumor malignancy. Invading tumor cells render complete surgical resection impossible, and recurrence of tumor growth therefore remains an intractable clinical issue. It is believed that glioma cells undergo EMTlike activity that is associated with $N F 1$ loss or dysregulation. Although NF1 is one of the most mutated genes and its GRD domain has been studied extensively, very limited is known about its other domains such as NF1-LRD domain in which mutations have been reported in GBM patients. In this study, we demonstrate that the NF1-LRD domain of $N F 1$ plays a role in glioma invasiveness.

It is known that $N F 1$ depletion results in hyperactivation of Ras and the subsequent activation of its downstream signaling such as EMT-related transcription factors. Our findings are in agreement with published report [20, 21] 
Fig. 4 Pathogenic mutations in the NF1-LRD domain abolish suppression of invasion. a Oncomap shows the distribution of point mutations in the NF1LRD domain. Mutations were derived from query performed on cBioportal TCGA dataset. b Invasion was assessed in neurofibromin-negative (i) LN229 and (ii) U251MG transduced with $\mathrm{pCDH}$, wtLRD, W1952* and D1849N.

The percentage of invasive cells was normalized to that of $\mathrm{pCDH}$ vector. c Percentage of invasion was performed on

neurofibromiin-negative (i) NNI-19 and (ii) NNI-24 patientderived GPCs transduced with pCDH, wt-LRD, W1952*, and D1849N. $n=4$ replicates. Immunoblot demonstrated expression of NF1-LRD as determine by HA expression. Actin serves as loading control. Densitometry quantification was performed by normalizing NF1LRD expression to actin. Ratios were indicated below the blot. All data are presented as mean \pm SEM from three independent experiment, $n=5$ replicates. Student's unpaired $t$ test was used to analyze statistical significance between wt and mutant LRD to that of vector, $* p<0.01, * * p<0.001, * * * p<$ 0.0001

A

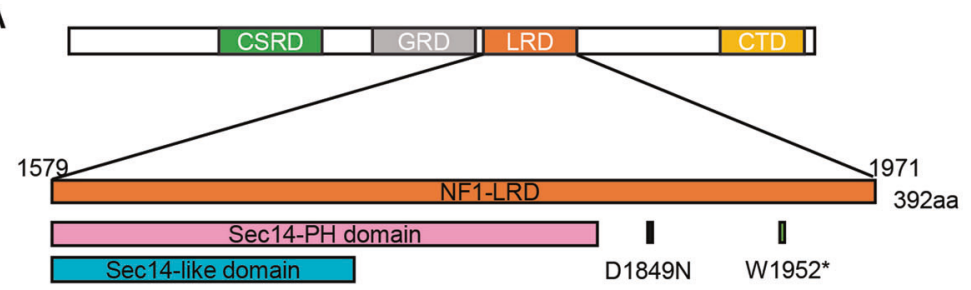

\section{B}

(i)

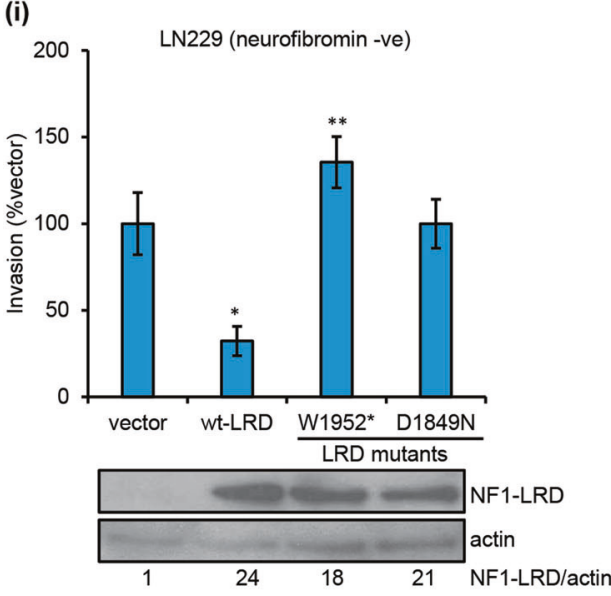

C

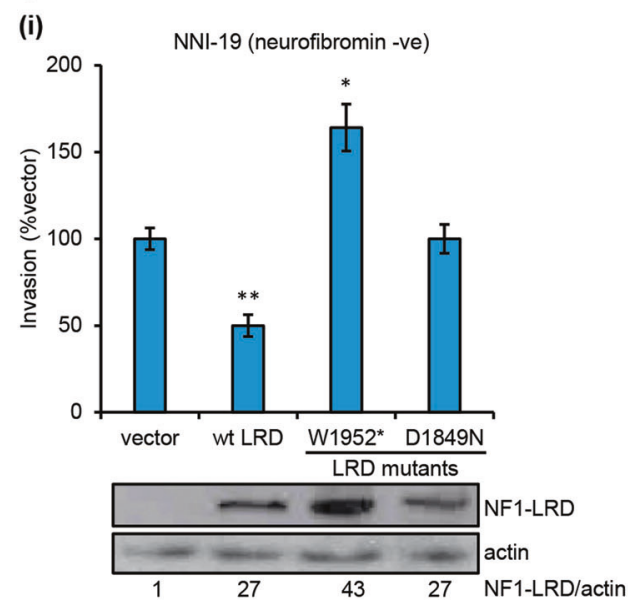

(ii)

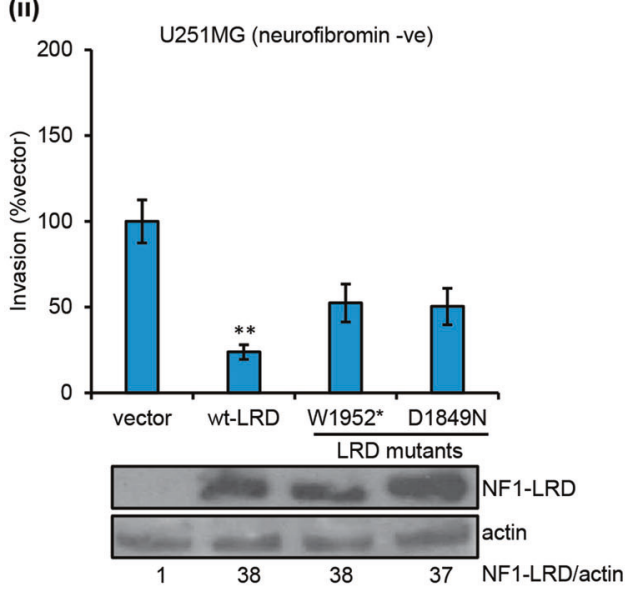

(ii)

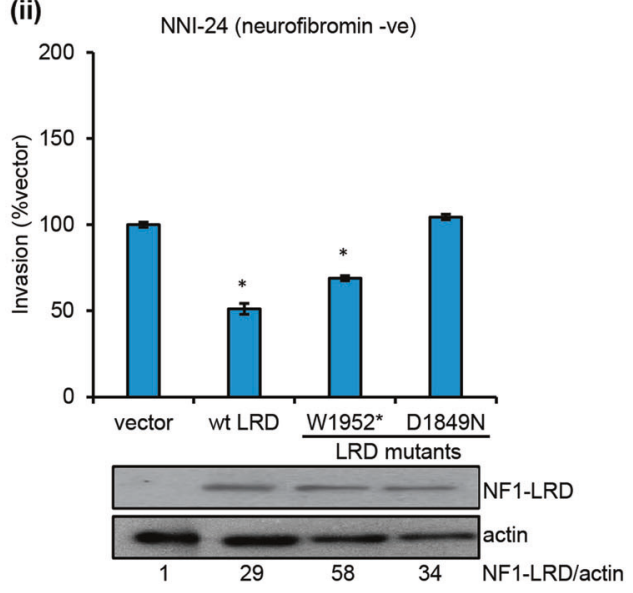

whereby loss of NF1 by shRNA promoted glioma cell invasion and upregulation of EMT markers such as vimentin, SNAI, TWIST1, ZEB1, and ZEB2. By contrast, the proneural marker SOX2 was downregulated, consistent with previous publication in head and neck cancer on the inverse relationship between SOX2 and vimentin [55]. Furthermore, we detected upregulation of p-70S6K and pAkt in GPCs transduced with NF1-shRNA, confirming the observation of Qian et al. [56] that AKT modulates cell migration and invasion through the activation of p-70S6K. In fact, AKT localize at the leading edge of migrating cells [57-60] to enhance actin cytoskeleton rearrangement as well as formation of membrane protrusion required for cell movement [61], and to modulate matrix metalloproteinase-2 and -9 expression [62, 63]. In terms of EMT-associated transcription factors, AKT activates TWIST1, but at the same time, it is also a TWIST1-mediated transcriptional regulator [64]. Notably, we showed that re-expression of NF1-LRD similarly reversed cellular invasiveness in several human glioma cell lines, patient-derived GPCs and an orthotopic mouse glioma model. Consistent with NF1 knockdown, this NF1-LRD-induced suppression of invasion correlates with increased SOX2 expression and reduced vimentin, SNAI1 and ZEB2 expression. However, re-expression of NF1-LRD suppresses cell invasion but only marginally downregulates p-Akt (Supplemental Fig. 5), suggesting that the NF1-LRD domain likely exerts its influence collaboratively with other neurofibromin domains 
A

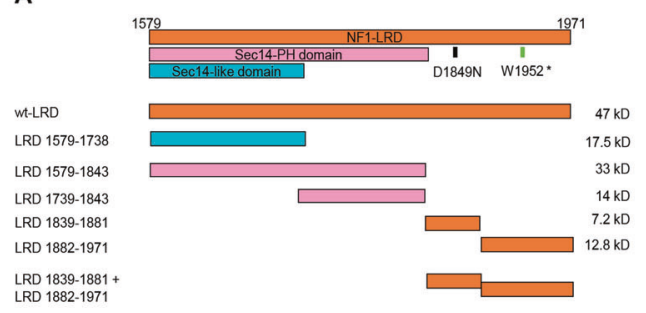

D

(i)

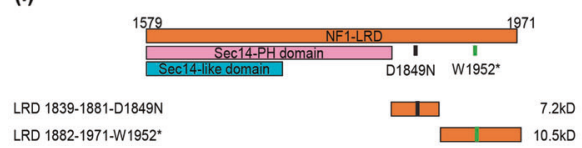

(ii)

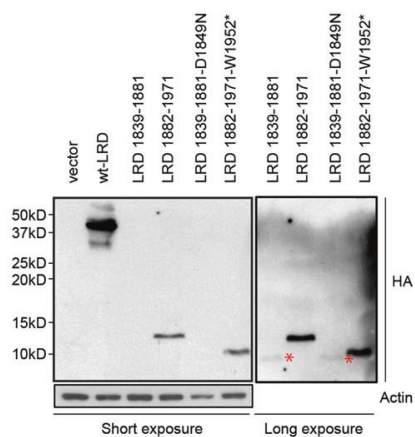

Fig. 5 C-terminal region of NF1-LRD domain is required for suppressing cell invasion. a Truncation mutants used in this study. b Western blot shows the expression of the various truncation mutants as determine by immunblotting for HA. Actin serves as loading control. $\mathbf{c}$ Invasion assay was performed to determine the region of NF1LRD that is necessary for suppressing cell invasion. (i) Percentage of invasion was calculated based on the number of HA+ cells vs. HAcells followed by normalizing to vector-transfected cells. DAPI stained the nucleus. (ii) Representative images showed HA+ cells vs. HAcells in the membrane. Data are presented as quadruplicate \pm SEM. Representative result from five independent experiment was shown. Student's unpaired $t$ test was used statistical analysis, $* p<0.01$,

such as the NF1-GRD, which inhibits proliferation through the RAS/AKT pathway in NF1-shRNA transduced cells, or other independent binding partners in the neurofibromindeficient LN229 and U251MG.

Although we showed that NF1-LRD and its peptides suppress cell invasion, we are cognizant of the limitation of our study is the location of the NF1-LRD domain within neurofibromin and the functional context of NF1-LRD in the full neurofibromin protein. In this study, we defined the NF1-LRD domain as previously reported, i.e., aa 1579-1971 neurofibromin isoform 1 (aa 1558-1950 neurofibromin isoform 2) $[35,41,54]$. This region contains the SEC14-PH domain (aa 1579-1843 neurofibromin isoform 1) and the undefined domain from aa 1839-1971. Aside from the known mutations found within the SEC14-PH domain, the 1839-1971 region harbors several missense mutations that

(i)

(ii)

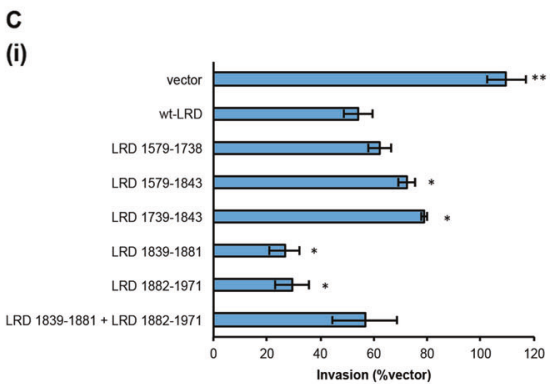

(ii)

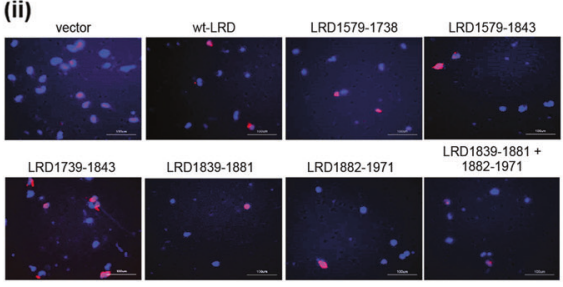

C

Invasion (\%vector)

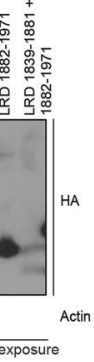

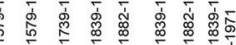

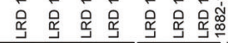

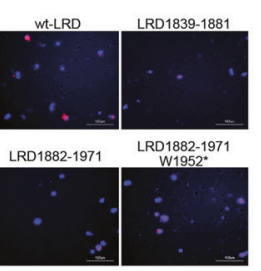

$* * p<0.001$, *** $p<0.0001$. d (i) D1849N and W1952* mutations were introduced into LRD 1839-1881 and LRD 1882-1971, respectively. (ii) Western blot shows the expression of the mutants as determined by HA. Actin serves as loading control. e Effect of point mutations in the peptides LRD 1839-1881 and LRD 1882-1971 was assessed. (i) Percentage of invasion was calculated based on the number of $\mathrm{HA}+$ cells vs. HA - cells followed by normalizing to vector-transfected cells. (ii) Representative images showed $\mathrm{HA}+$ cells vs. HA - cells in the membrane. DAPI stained the nucleus. Data are presented as quadruplicate \pm SEM. Student's unpaired $t$ test was used statistical analysis, $* p<0.01, * * p<0.001, * * * p<0.0001$

were suggested to be pathogenic (dbSNP and cBioportal) $[11,12,65]$. Based on results from Hsueh's group [41] and ours, we postulate that this region define the boundary of the NF1-LRD domain. Our assumption is based on the observation that point mutations generated within the NF1LRD domain (D1849N and W1952*) abolished cell invasion of glioma cells lines and non-NF1-patient-derived glioma cells (Fig. 4). In addition, truncation mutants 1839 1881 and 1882-1971 individually suppressed cell invasion 50\% higher than wt-NF1-LRD (Fig. 5). Mutations within these two peptides completely abolished their function, indicating that the region 1839-1971 is functional. It is important to note that although both D1849N and W1952* mutations identified from cancer databases help to dissect the functional significance of NF1-LRD in GBM, they are nevertheless different from mutations identified from NF1 
patients who may have increased susceptibility to NF1associated glioma.

The LRD 1839-1971 peptide region coincides with a portion of the HLR. The HLR is composed of two linked alpha helices that are structurally related to the coiled coil domain of ARM repeats that are similarly found in Plakoglobin, also known as $\gamma$-catenin. In breast cancer cells, Plakoglobin is involved in the translocation of E-cadherin and $\beta$-catenin to inhibit cell invasion [66-69]. While the functionality of the NF1-LRD has yet to be elucidated in the context of full neurofibromin protein, it has been hypothesized that NF1-LRD may function as a scaffold protein to interact with phospholipids for membrane localization owing to its SEC14 domain [42] that is adjacent to the GAP domain and the PH-like domain that associate with proteins involved in signal transduction [70]. In addition, the HLR domain may also function in protein-protein interaction. Since the induction of the invasive phenotype requires cooperation between multiple factors, it is possible that the NF1-LRD may independently interacts with other proteins to bring about its suppressive effect. Future work may entail the elucidation of the 3D structure of NF1-LRD and the full neurofibromin protein to decipher its active binding region as well as conformation. Currently, the crystal structure of NF1-LRD is not available due to its poor stability even with the used of codonoptimized constructs [71]. However, this issue may be overcome with the use of the cloning-friendly NF1 mini-genes by the Morrison's group [72], which may also aid in identification of the potential interaction partner(s).

In summary, our results show, for the first time, the NF1LRD domain reverts NF1-loss induced invasion, and provides initial evidence into the otherwise novel function of NF1-LRD in glioma biology.

\section{Materials and methods}

\section{Cell culture and transfection}

This study was approved by the Centralized Institutional Review Board of SingHealth (Singapore). Patient-derived GPCs are kind gifts from Drs Ang BT and Tang C (National Neuroscience Institute, Singapore) after informed consent. A total of four GPCs isolates were used in this study; these are NNI-12, NNI-21, NNI-19, and NNI-24. The GPCs were cultured in Dulbecco's Modified Eagle's Media (DMEM)/ F12 (Sigma-Aldrich, Inc., MO, USA) supplemented with B27 (Invitrogen, Carlsbad, CA), EGF (R\&D Systems, Minneapolis, MN), basic fibroblast growth factor (R\&D Systems) and heparin (Sigma-Aldrich, Inc.). Human glioma cell lines U87MG, U251MG and LN229 were obtained from American Type Cell Culture (ATCC, Manassas, VA) and authenticated in 2017 and confirmed mycoplasma negative by service provider. These cells were cultured in DMEM with $10 \%$ fetal bovine serum (FBS) (Invitrogen).

For in vitro transfection, $2-12 \mu \mathrm{g}$ of plasmid DNA were transfected into $0.3-2.5 \times 10^{6}$ human glioma cells using Viafect $^{\mathrm{TM}}$ (Promega, Madison, WI) or polyethylenimine, linear, MW 25000 (PEI) (Polysciences, Inc., Warrington, PA) in accordance with the manufacturer's instructions.

\section{Plasmids}

shCtrl and NF1-shRNA with the pGFP-shLenti backbone were obtained from OriGene (OriGene, Rockville, MD). The plasmids, HA-LRD, HA-GRD, HA-CSRD, and HACTD, in pGW1 backbone, are kind gift from Dr Hsueh YP (Academia Sinica, Taiwan). To generate deletion mutants of NF1-LRD, sequences encoding for the various mutants were synthesized (Integrated DNA Technologies, Inc., Coralville, IA) and subcloned into BglII site of pGW1-HA. All sequences were verified by DNA sequencing (1st BASE, Singapore). Refer to Supplementary methods for full method.

\section{Invasion assay}

Invasion assay was performed using Corning ${ }^{\circledR}$ Matrigel $^{\circledR}$ Invasion Chamber according to manufacturer's instructions (Corning Incorporated, Corning, NY). Briefly, GPCs or glioma cells $\left(5 \times 10^{4}\right)$ suspended in either DMEM/F12 medium or DMEM containing 5\% FBS were added to the top chamber. DMEM containing $10 \%$ FBS was added the bottom chamber. The extent of invasion was quantified after $24 \mathrm{~h}$ by counting the number of invasive cells at the underside of the chamber at original magnification $\mathrm{x} 200$. All assays were performed in quadruplicates, and images from five random fields were taken for each replicate. Refer Supplementary methods for full method.

\section{Quantitative real-time PCR}

Quantitative real-time PCR was performed as described previously [73]. Expression levels of the various targets were quantified using LightCycler 96 (Roche Holding AG, Basel, Switzerland). All qPCR reactions were performed in duplicate. Expression level was calculated using the ddCT method. The relative expression level was calculated by arbitrarily designating the lowest normalized value to 1 .

\section{Immunoblotting}

Proteins were extracted from cells in RIPA buffer $(10 \mathrm{mM}$ Tris $\mathrm{pH} 7.4,1 \times$ IGEPAL, $0.5 \%$ sodium deoxycholate, $0.1 \%$ sodium dodecyl sulfate) containing phosphatase and protease inhibitor (Roche). For detection of neurofibromin 
Table 1 List of antibodies used

\begin{tabular}{ll}
\hline Protein target & Manufacturer and cat. no. \\
\hline 3-Actin (C4) & Santa Cruz sc-47778 \\
Neurofibromin (H-12) & Santa Cruz sc-376886 \\
Neurofibromin (D) & Santa Cruz sc-67 \\
HA-Tag (C29F4) & Cell Signaling \#3724 \\
Phospho-Akt (Ser473) & Cell Signaling \#9271 \\
Akt & Cell Signaling \#9272 \\
Phospho-Stat3 (Ser727) & Cell Signaling \#9134 \\
Stat3 (79D7) & Cell Signaling \#4904 \\
Phospho-p70 S6 Kinase (Thr389) (1A5) & Cell Signaling \#9206 \\
p70 S6 Kinase & Cell Signaling \#9202 \\
Phospho-p38 MAPK (Thr180/Tyr182) & Cell Signaling \#4511 \\
(D3F9) XP & \\
p38 MAPK & Cell Signaling \#9212 \\
Phospho-S6 ribosomal protein (Ser235/ & Cell Signaling \#4858 \\
236) (D57.2.2E) XP & \\
S6 ribosomal protein (5G10) & Cell Signaling \#2217 \\
Phospho-SMAD2 (pSer465/467) & Merck \#566415 \\
SMAD2/3 (C-8) & Santa Cruz sc-133098 \\
HSP90 & Cell Signaling \#4874 \\
CD44std (SFF-304) & eBioScienceTM BMS150 \\
Vimentin (D21H3) XP & Cell Signaling \#5741 \\
SOX2 & R\&D Systems MAB2018 \\
Anti-mouse IgG, HRP-linked & Cell Signaling \#7076 \\
Anti-rabbit IgG, HRP-linked & Cell Signaling \#7074 \\
\hline
\end{tabular}

expression, denatured protein samples were resolved in 3$8 \%$ tris-Acetate gel (Invitrogen) followed by transferred onto a $0.45 \mu \mathrm{m}$ polyvinylidene fluoride membrane (Merck \& Co., Kenilworth, NJ), which was then blocked in 5\% milk in Tris-buffered saline containing $0.1 \%$ Tween-20 and probed with the required antibodies. Membranes were blotted against the following antibodies: NF1(D), NF1 (H-12), and $\beta$-actin (C4) (Santa Cruz Biotechnology, Inc., Dallas, TX); phospho-p38, total p38, phospho-STAT3 (Ser727), total STAT3, phospho-AKT (Ser473), total AKT, phospho-p70S6K (Thr389), total p70S6K, phosphoS6 ribosomal protein, total S6, HA-Tag (C29F4), pSMAD2, total SMAD2, and HSP90 (Cell Signaling Technology, Inc., Danvers, MA). List of antibodies used are shown in Table 1. Refer to Supplementary methods for full methods.

\section{Immunofluorescence and immunohistochemistry staining}

Immunohistochemistry analysis was performed on $5 \mu \mathrm{m}$ thick paraffin-embedded 4\% PFA fixed tissue sections with the following primary antibodies diluted in PBS containing $0.1 \%$ Tween-20, $3 \%$ goat serum and $0.1 \%$ bovine serum albumin: CD44std (SFF-304, 1:50 dilution, eBiosciences, Thermo Fisher Scientific), SOX2 (Clone \#245610, 1:300 dilution, R\&D Systems Inc.), NF1 (D) (sc-67, 1:100 dilution), and Vimentin (D21H3, 1:25 dilution, Cell Signaling Technology, Inc.). Target protein expression was detected using DAB followed by counterstaining with hematoxylin and visualized with an inverted microscope (Eclipse TE2000-S, Nikon, Japan) at $20 \times / 0.45$ numerical aperture (N.A.) Plan Fluor objective (Nikon) or $60 \times$ objective. Images were quantified from 8-10 sections using ImmunoRatio, an ImageJ (NIH) plugin that uses deconvolution algorithm to separate and quantify nuclear staining using DAB [74]. For immunofluorescence staining, cells fixed with 4\% PFA was incubated with anti-HA antibody followed by Alexa-Fluor 594 conjugated secondary antibody incubation. All immunofluorescence-stained samples were examined under confocal microscope (FV1000, Olympus, Japan) at $20 \times / 0.75$ N.A. UPlanSApo objective (Olympus). Refer to Supplementary methods for full method.

\section{In vivo tumor implantation}

All animal experiments were performed in accordance to the guidelines and protocols approved by the Institutional Animal Care and Use Committee at National Neuroscience Institute, Singapore. Inoculation of tumor cells in immunodeficient mice was performed as previously described [75]. GPCs were preinfected with multiplicity of infection 50 of either shCtrl, $N F 1$-shRNA, pCDH, or NF1-LRD viral vectors. Transduced cells $\left(5 \times 10^{5}\right.$ cells $)$ were implanted into the right hemisphere (Bregma 0,0, lateral $2 \mathrm{~mm}$, anterior 1 $\mathrm{mm}$, depth $-2.5 \mathrm{~mm}$ ) of six male immunodeficient NSG mice (InVivos, Singapore) of 6- to 8-week old. The number of animals injected with the tumor cells were determined based on our experience, where 6 mice are sufficient to demonstrate approximately 50\% difference in tumor growth. Glioma-bearing mice were sacrificed 2 months post-tumor implantation when neurological deficit such as cachexia, hunched-back, and lethargy was observed. No randomization was used. Investigators were not blinded during analysis.

To assess the extent of tumor cells invasion, mice were perfused through the heart with ice-cold saline followed by $4 \%$ paraformaldehyde (PFA). Mice brains were harvested and kept in $4 \%$ PFA overnight at $4{ }^{\circ} \mathrm{C}$, transferred to $30 \%$ sucrose in PBS for additional $48 \mathrm{~h}$ prior to paraffin embedding or cyrosectioning.

\section{Statistical analysis}

All results were presented as mean \pm SEM with the exception of Fig. 1a. Figure 1a was presented as mean \pm S.D. All in vitro experiments were performed in three to eight 
replicates and were repeated at least thrice independently. Statistical analysis was performed using Prism 6.0 (Graphpad Software, Inc., La Jolla, CA). One-way analysis of variance followed by Tukey-Kramer or Bonferroni multiple comparisons test were used for comparing statistical significance for more than two groups. Unpaired twosided Student's $t$ test was used for comparing between two groups of equal variance. $p$ Value $<0.05$ was considered statistically significant.

Acknowledgements We thank Amirah Mohammad Yusof, Jolene WL Lee, and Joseph Ho for technical assistant.

Funding This project is funded by grants from NCC Research Fund and Oncology Academic Program (NCCRF-OACPCCS-YR2014AUG-3), National Medical Research Council (NMRC/OFIRG/0039/ 2017), and institutional center grant to IAWH. This work is also partially supported by the Singapore Ministry of Health's National Medical Research Council under its Translational and Clinical Research (TCR) Flagship Program-Tier 1 (Project No. NMRC/TCR/ 016-NNI/2016) awarded to BTA and CT.

Author contributions IAWH conceived and designed the overall research. SFF, NAH, JYTY, RLYH and PU performed the research and analyzed the data. WHN, CT and BTA contributed the reagents. IAWH wrote and reviewed the paper with valuable input from DMV.

\section{Compliance with ethical standards}

Conflict of interest The authors declare that they have no conflict of interest.

Publisher's note: Springer Nature remains neutral with regard to jurisdictional claims in published maps and institutional affiliations.

Open Access This article is licensed under a Creative Commons Attribution 4.0 International License, which permits use, sharing, adaptation, distribution and reproduction in any medium or format, as long as you give appropriate credit to the original author(s) and the source, provide a link to the Creative Commons license, and indicate if changes were made. The images or other third party material in this article are included in the article's Creative Commons license, unless indicated otherwise in a credit line to the material. If material is not included in the article's Creative Commons license and your intended use is not permitted by statutory regulation or exceeds the permitted use, you will need to obtain permission directly from the copyright holder. To view a copy of this license, visit http://creativecommons. org/licenses/by/4.0/.

\section{References}

1. Stupp R, Mason WP, van den Bent MJ, Weller M, Fisher B, Taphoorn MJ, et al. Radiotherapy plus concomitant and adjuvant temozolomide for glioblastoma. N Engl J Med. 2005;352:987-96.

2. Johnson DR, O'Neill BP. Glioblastoma survival in the United States before and during the temozolomide era. J Neurooncol. 2012;107:359-64.

3. Verhaak RG, Hoadley KA, Purdom E, Wang V, Qi Y, Wilkerson $\mathrm{MD}$, et al. Integrated genomic analysis identifies clinically relevant subtypes of glioblastoma characterized by abnormalities in PDGFRA, IDH1, EGFR, and NF1. Cancer Cell. 2010;17:98-110.
4. Phillips HS, Kharbanda S, Chen R, Forrest WF, Soriano RH, Wu $\mathrm{TD}$, et al. Molecular subclasses of high-grade glioma predict prognosis, delineate a pattern of disease progression, and resemble stages in neurogenesis. Cancer Cell. 2006;9:157-73.

5. Parsons DW, Jones S, Zhang X, Lin JC, Leary RJ, Angenendt P, et al. An integrated genomic analysis of human glioblastoma multiforme. Science. 2008;321:1807-12.

6. McGillicuddy LT, Fromm JA, Hollstein PE, Kubek S, Beroukhim R, De Raedt T, et al. Proteasomal and genetic inactivation of the NF1 tumor suppressor in gliomagenesis. Cancer Cell. 2009;16:44-54.

7. The I, Murthy AE, Hannigan GE, Jacoby LB, Menon AG, Gusella $\mathrm{JF}$, et al. Neurofibromatosis type 1 gene mutations in neuroblastoma. Nat Genet. 1993;3:62-6.

8. Maertens O, Johnson B, Hollstein P, Frederick DT, Cooper ZA, Messiaen L, et al. Elucidating distinct roles for NF1 in melanomagenesis. Cancer Discov. 2013;3:338-49.

9. Ding L, Getz G, Wheeler DA, Mardis ER, McLellan MD, Cibulskis K, et al. Somatic mutations affect key pathways in lung adenocarcinoma. Nature. 2008;455:1069-75.

10. Cancer Genome Atlas Research N. Comprehensive genomic characterization defines human glioblastoma genes and core pathways. Nature. 2008;455:1061-8.

11. Cerami E, Gao J, Dogrusoz U, Gross BE, Sumer SO, Aksoy BA, et al. The cBio cancer genomics portal: an open platform for exploring multidimensional cancer genomics data. Cancer Discov. 2012;2:401-4.

12. Gao J, Aksoy BA, Dogrusoz U, Dresdner G, Gross B, Sumer SO, et al. Integrative analysis of complex cancer genomics and clinical profiles using the cBioPortal. Sci Signal. 2013;6:pl1.

13. Herting CJ, Chen Z, Pitter KL, Szulzewsky F, Kaffes I, Kaluzova $\mathrm{M}$, et al. Genetic driver mutations define the expression signature and microenvironmental composition of high-grade gliomas. Glia. 2017;65:1914-26.

14. Ozawa T, Riester M, Cheng YK, Huse JT, Squatrito M, Helmy K, et al. Most human non-GCIMP glioblastoma subtypes evolve from a common proneural-like precursor glioma. Cancer Cell. 2014;26:288-300.

15. Alcantara Llaguno SR, Wang Z, Sun D, Chen J, Xu J, Kim E, et al. Adult lineage-restricted CNS progenitors specify distinct glioblastoma subtypes. Cancer Cell. 2015;28:429-40.

16. Chow RD, Guzman CD, Wang G, Schmidt F, Youngblood MW, Ye L, et al. AAV-mediated direct in vivo CRISPR screen identifies functional suppressors in glioblastoma. Nat Neurosci. 2017;20:1329-41.

17. Sintupisut N, Liu PL, Yeang CH. An integrative characterization of recurrent molecular aberrations in glioblastoma genomes. Nucleic Acids Res. 2013;41:8803-21.

18. Cichowski K, Jacks T. NF1 tumor suppressor gene function: narrowing the GAP. Cell. 2001;104:593-604.

19. Zhu Y, Parada LF. Neurofibromin, a tumor suppressor in the nervous system. Exp Cell Res. 2001;264:19-28.

20. Arima Y, Hayashi H, Kamata K, Goto TM, Sasaki M, Kuramochi A, et al. Decreased expression of neurofibromin contributes to epithelial-mesenchymal transition in neurofibromatosis type 1 . Exp Dermatol. 2010;19:e136-41.

21. Miller SJ, Rangwala F, Williams J, Ackerman P, Kong S, Jegga AG, et al. Large-scale molecular comparison of human schwann cells to malignant peripheral nerve sheath tumor cell lines and tissues. Cancer Res. 2006;66:2584-91.

22. Vallee B, Doudeau M, Godin F, Gombault A, Tchalikian A, de Tauzia ML, et al. Nf1 RasGAP inhibition of LIMK2 mediates a new cross-talk between Ras and Rho pathways. PLoS ONE. 2012; 7:e47283.

23. Whittaker SR, Theurillat JP, Van Allen E, Wagle N, Hsiao J, Cowley GS, et al. A genome-scale RNA interference screen 
implicates NF1 loss in resistance to RAF inhibition. Cancer Discov. 2013;3:350-62.

24. Nissan MH, Pratilas CA, Jones AM, Ramirez R, Won H, Liu C, et al. Loss of NF1 in cutaneous melanoma is associated with RAS activation and MEK dependence. Cancer Res. 2014;74:2340-50.

25. Mendes-Pereira AM, Sims D, Dexter T, Fenwick K, Assiotis I, Kozarewa I, et al. Genome-wide functional screen identifies a compendium of genes affecting sensitivity to tamoxifen. Proc Natl Acad Sci USA. 2012;109(8):2730-5.

26. Holzel M, Huang S, Koster J, Ora I, Lakeman A, Caron H, et al. NF1 is a tumor suppressor in neuroblastoma that determines retinoic acid response and disease outcome. Cell. 2010;142:218-29.

27. de Bruin EC, Cowell C, Warne PH, Jiang M, Saunders RE, Melnick MA, et al. Reduced NF1 expression confers resistance to EGFR inhibition in lung cancer. Cancer Discov. 2014;4:606-19.

28. Guo J, Grovola MR, Xie H, Coggins GE, Duggan P, Hasan R, et al. Comprehensive pharmacological profiling of neurofibromatosis cell lines. Am J Cancer Res. 2017;7:923-34.

29. Ambrosini G, Cheema HS, Seelman S, Teed A, Sambol EB, Singer S, et al. Sorafenib inhibits growth and mitogen-activated protein kinase signaling in malignant peripheral nerve sheath cells. Mol Cancer Ther. 2008;7:890-6.

30. Dodd RD, Mito JK, Eward WC, Chitalia R, Sachdeva M, Ma Y, et al. NF1 deletion generates multiple subtypes of soft-tissue sarcoma that respond to MEK inhibition. Mol Cancer Ther. 2013;12:1906-17.

31. Maki RG, D'Adamo DR, Keohan ML, Saulle M, Schuetze SM, Undevia SD, et al. Phase II study of sorafenib in patients with metastatic or recurrent sarcomas. J Clin Oncol. 2009;27:3133-40.

32. Dombi E, Baldwin A, Marcus LJ, Fisher MJ, Weiss B, Kim A, et al. Activity of selumetinib in neurofibromatosis type 1-related plexiform neurofibromas. N Engl J Med. 2016;375:2550-60.

33. Kahen EJ, Brohl A, Yu D, Welch D, Cubitt CL, Lee JK, et al. Neurofibromin level directs RAS pathway signaling and mediates sensitivity to targeted agents in malignant peripheral nerve sheath tumors. Oncotarget. 2018;9:22571-85.

34. Hsueh YP. From neurodevelopment to neurodegeneration: the interaction of neurofibromin and valosin-containing protein/p97 in regulation of dendritic spine formation. J Biomed Sci. 2012;19:33.

35. Tokuo H, Yunoue S, Feng L, Kimoto M, Tsuji H, Ono T, et al. Phosphorylation of neurofibromin by cAMP-dependent protein kinase is regulated via a cellular association of $N^{\mathrm{G}}, N^{\mathrm{G}}$-dimethylarginine dimethylaminohydrolase. FEBS Lett. 2001;494:48-53.

36. Stowe IB, Mercado EL, Stowe TR, Bell EL, Oses-Prieto JA, Hernandez $\mathrm{H}$, et al. A shared molecular mechanism underlies the human rasopathies Legius syndrome and neurofibromatosis-1. Genes Dev. 2012;26:1421-6.

37. Feng L, Yunoue S, Tokuo H, Ozawa T, Zhang D, Patrakitkomjom S, et al. PKA phosphorylation and 14-3-3 interaction regulate the function of neurofibromatosis type 1 tumor suppressor, neurofibromin. FEBS Lett. 2004;557:275-82.

38. Patrakitkomjom S, Kobayashi D, Morikawa T, Wilson MM, Tsubota N, Irie A, et al. Neurofibromatosis type 1 (NF1) tumor suppressor, neurofibromin, regulates the neuronal differentiation of PC12 cells via its associating protein, CRMP-2. J Biol Chem. 2008;283:9399-413.

39. Lin Y-L, Lei Y-T, Hong C-J, Hsueh YP. Syndecan-2 induces filopodia formation via the neurofibromin-PKA-Ena/VASP pathway. J Cell Biol. 2007;177:829-41.

40. Kweh F, Zheng M, Kurenova E, Wallace M, Golubovskaya V, Cance WG. Neurofibromin physically interacts with the Nterminal domain of focal adhesion kinase. Mol Carcinog. 2009;48:1005-17.

41. Wang HF, Shih YT, Chen CY, Chao HW, Lee MJ, Hsueh YP. Valosin-containing protein and neurofibromin interact to regulate dendritic spine density. J Clin Invest. 2011;121:4820-37.
42. Welti S, Fraterman S, D'Angelo I, Wilm M, Scheffzek K. The sec14 homology module of neurofibromin binds cellular glycerophospholipids: mass spectrometry and structure of a lipid complex. J Mol Biol. 2007;366:551-62.

43. D'Angelo I, Welti S, Bonneau F, Scheffzek K. A novel bipartite phospholipid-binding module in the neurofibromatosis type 1 protein. EMBO Rep. 2006;7:174-9.

44. Brennan C, Momota H, Hambardzumyan D, Ozawa T, Tandon A, Pedraza A, et al. Glioblastoma subclasses can be defined by activity among signal transduction pathways and associated genomic alterations. PLoS ONE. 2009;4:e7752.

45. Alcantara Llaguno S, Chen J, Kwon CH, Jackson EL, Li Y, Burns $\mathrm{DK}$, et al. Malignant astrocytomas originate from neural stem/ progenitor cells in a somatic tumor suppressor mouse model. Cancer Cell. 2009;15:45-56.

46. Joseph NM, Mosher JT, Buchstaller J, Snider P, McKeever PE, Lim M, et al. The loss of Nf1 transiently promotes self-renewal but not tumorigenesis by neural crest stem cells. Cancer Cell. 2008;13:129-40.

47. Chong YK, Toh TB, Zaiden N, Poonepalli A, Leong SH, Ong CE, et al. Cryopreservation of neurospheres derived from human glioblastoma multiforme. Stem Cells. 2009;27:29-39.

48. Foong CS, Ng FS, Phong M, Toh TB, Chong YK, TuckerKellogg G, et al. Cryopreservation of cancer-initiating cells derived from glioblastoma. Front Biosci. 2011;3:698-708.

49. Koh LW, Koh GR, Ng FS, Toh TB, Sandanaraj E, Chong YK, et al. A distinct reactive oxygen species profile confers chemoresistance in glioma-propagating cells and associates with patient survival outcome. Antioxid Redox Signal. 2013;19:226179.

50. Ng FS, Toh TB, Ting EH, Koh GR, Sandanaraj E, Phong M, et al. Progenitor-like traits contribute to patient survival and prognosis in oligodendroglial tumors. Clin Cancer Res. 2012;18:4122-35.

51. Berezovsky AD, Poisson LM, Cherba D, Webb CP, Transou AD, Lemke NW, et al. Sox 2 promotes malignancy in glioblastoma by regulating plasticity and astrocytic differentiation. Neoplasia. 2014;16:193-206. 206 e119-125

52. Lee JK, Joo KM, Lee J, Yoon Y, Nam DH. Targeting the epithelial to mesenchymal transition in glioblastoma: the emerging role of MET signaling. OncoTargets Ther. 2014;7:1933-44.

53. Brown DV, Daniel PM, D'Abaco GM, Gogos A, Ng W, Morokoff AP, et al. Coexpression analysis of CD133 and CD44 identifies proneural and mesenchymal subtypes of glioblastoma multiforme. Oncotarget. 2015;6:6267-80.

54. Ratner N, Miller SJ. A RASopathy gene commonly mutated in cancer: the neurofibromatosis type 1 tumour suppressor. Nat Rev Cancer. 2015;15:290-301.

55. Bayo P, Jou A, Stenzinger A, Shao C, Gross M, Jensen A, et al. Loss of SOX2 expression induces cell motility via vimentin upregulation and is an unfavorable risk factor for survival of head and neck squamous cell carcinoma. Mol Oncol. 2015;9:1704-19.

56. Qian Y, Corum L, Meng Q, Blenis J, Zheng JZ, Shi X, et al. PI3K induced actin filament remodeling through Akt and p70S6K1: implication of essential role in cell migration. Am J Physiol Cell Physiol. 2004;286:C153-63.

57. Kim D, Kim S, Koh H, Yoon SO, Chung AS, Cho KS, et al. Akt/ PKB promotes cancer cell invasion via increased motility and metalloproteinase production. FASEB J. 2001;15:1953-62.

58. Wang KZ, Wara-Aswapati N, Boch JA, Yoshida Y, Hu CD, Galson DL, et al. TRAF6 activation of PI 3-kinase-dependent cytoskeletal changes is cooperative with Ras and is mediated by an interaction with cytoplasmic Src. J Cell Sci. 2006;119:157991.

59. Fortier AM, Asselin E, Cadrin M. Keratin 8 and 18 loss in epithelial cancer cells increases collective cell migration and cisplatin 
sensitivity through claudin1 up-regulation. J Biol Chem. 2013;288:11555-71.

60. Yamaguchi N, Mizutani T, Kawabata K, Haga H. Leader cells regulate collective cell migration via Rac activation in the downstream signaling of integrin beta1 and PI3K. Sci Rep. 2015;5:7656.

61. Scita G, Tenca P, Frittoli E, Tocchetti A, Innocenti M, Giardina G, et al. Signaling from Ras to Rac and beyond: not just a matter of GEFs. EMBO J. 2000;19:2393-8.

62. Kwiatkowska A, Kijewska M, Lipko M, Hibner U, Kaminska B. Downregulation of Akt and FAK phosphorylation reduces invasion of glioblastoma cells by impairment of MT1-MMP shuttling to lamellipodia and downregulates MMPs expression. Biochim Biophys Acta. 2011;1813:655-67.

63. Pu P, Kang C, Li J, Jiang H, Cheng J. The effects of antisense AKT2 RNA on the inhibition of malignant glioma cell growth in vitro and in vivo. J Neurooncol. 2006;76:1-11.

64. Cheng GZ, Zhang W, Wang LH. Regulation of cancer cell survival, migration, and invasion by Twist: AKT2 comes to interplay. Cancer Res. 2008;68:957-60.

65. Sherry ST, Ward MH, Kholodov M, Baker J, Phan L, Smigielski EM, et al. dbSNP: the NCBI database of genetic variation. Nucleic Acids Res. 2001;29:308-11.

66. Boissan M, De Wever O, Lizarraga F, Wendum D, Poincloux R, Chignard N, et al. Implication of metastasis suppressor NM23-H1 in maintaining adherens junctions and limiting the invasive potential of human cancer cells. Cancer Res. 2010;70:7710-22.

67. Larue L, Bellacosa A. Epithelial-mesenchymal transition in development and cancer: role of phosphatidylinositol 3' kinase/ AKT pathways. Oncogene. 2005;24:7443-54.
68. Elston MS, Gill AJ, Conaglen JV, Clarkson A, Cook RJ, Little NS, et al. Nuclear accumulation of e-cadherin correlates with loss of cytoplasmic membrane staining and invasion in pituitary adenomas. J Clin Endocrinol Metab. 2009;94:1436-42.

69. Holen I, Whitworth J, Nutter F, Evans A, Brown HK, Lefley DV, et al. Loss of plakoglobin promotes decreased cell-cell contact, increased invasion, and breast cancer cell dissemination in vivo. Breast Cancer Res. 2012;14:R86.

70. Scheffzek K, Welti S. Pleckstrin homology (PH) like domains versatile modules in protein-protein interaction platforms. FEBS Lett. 2012;586:2662-73.

71. Bonneau F, Lenherr ED, Pena V, Hart DJ, Scheffzek K. Solubility survey of fragments of the neurofibromatosis type 1 protein neurofibromin. Protein Expr Purif. 2009;65:30-7.

72. Cui Y, Morrison H. Construction of cloning-friendly mini-genes for mammalian expression of full-length human NF1 isoforms. Hum Mutat. 2018;40:187-92.

73. Ho IA, Chan KY, Ng WH, Guo CM, Hui KM, Cheang P, et al. Matrix metalloproteinase 1 is necessary for the migration of human bone marrow-derived mesenchymal stem cells toward human glioma. Stem Cells. 2009;27:1366-75.

74. Tuominen VJ, Ruotoistenmaki S, Viitanen A, Jumppanen M, Isola J. ImmunoRatio: a publicly available web application for quantitative image analysis of estrogen receptor (ER), progesterone receptor (PR), and Ki-67. Breast Cancer Res. 2010;12:R56.

75. Yulyana Y, Endaya BB, Ng WH, Guo CM, Hui KM, Lam PY, et al. Carbenoxolone enhances TRAIL-induced apoptosis through the upregulation of death receptor 5 and inhibition of gap junction intercellular communication in human glioma. Stem Cells Dev. 2013;22:1870-82. 